\title{
Can organized leisure-time activities buffer the negative outcomes of unstructured activities for adolescents' health?
}

\author{
Petr Badura ${ }^{1,2}$ (1) - Andrea Madarasova Geckova ${ }^{1,3,4,5} \cdot$ Dagmar Sigmundova $^{1} \cdot$ \\ Erik Sigmund ${ }^{1} \cdot$ Jitse P. van Dijk ${ }^{2,3,5,6} \cdot$ Sijmen A. Reijneveld ${ }^{2}$
}

Received: 22 August 2017/Revised: 21 May 2018 / Accepted: 24 May 2018/Published online: 2 June 2018

(C) The Author(s) 2018

\begin{abstract}
Objectives We aimed to assess the associations of involvement in selected unstructured activities (UA) with health-risk behaviours and academic achievement and the degree to which the participation in organized leisure-time activities (OLTA) changes these associations.

Methods Using a sample of 6935 Czech adolescents aged 13 and 15 years, we investigated adolescents' weekly involvement in hanging out, visiting shopping malls for fun and meeting friends after 8 p.m., OLTA and engagement in three health-risk behaviours and academic achievement.

Results Weekly involvement in the selected UA was associated with higher odds for regular smoking, being drunk, having early sexual intercourse and low academic achievement. Concurrent participation in OLTA did not buffer these negative outcomes, except for sexual experience. However, those highly engaged only in UA were more likely to participate in the health-risk behaviours and report worse academic achievement than those participating in any OLTA concurrently.

Conclusions The selected UA are strongly associated with an increased occurrence of adolescents' health-risk behaviours and low academic achievement. Concurrent participation in OLTA does not buffer these negative outcomes significantly, but adolescents engaged only in UA consistently report the least favourable outcomes.
\end{abstract}

Keywords Adolescence $\cdot$ Extracurricular activities $\cdot$ Unstructured leisure $\cdot$ Substance use $\cdot$ Sexual intercourse $\cdot$ School performance

Petr Badura

petr.badura@upol.cz

Andrea Madarasova Geckova

andrea.geckova@upjs.sk

Dagmar Sigmundova

dagmar.sigmundova@upol.cz

Erik Sigmund

erik.sigmund@upol.cz

Jitse P. van Dijk

j.p.van.dijk@umcg.nl

Sijmen A. Reijneveld

s.a.reijneveld@umcg.nl
2 Department of Community and Occupational Medicine, University Medical Center Groningen, University of Groningen, Groningen, The Netherlands

3 Olomouc University for Society and Health Institute, Palacký University, Olomouc, Czech Republic

4 Department of Health Psychology, Faculty of Medicine, Safarik University, Kosice, Slovakia

5 Graduate School Kosice Institute for Society and Health, Safarik University, Kosice, Slovakia

6 Department of Social Medicine and Public Health, Faculty of Medicine and Dentistry, Palacký University, Olomouc, Czech Republic

1 Institute of Active Lifestyle, Faculty of Physical Culture, Palacký University, Tr. Miru 117, 77111 Olomouc, Czech Republic 


\section{Introduction}

In western industrialized countries, leisure time comprises approximately half of adolescents' waking hours, with a slightly higher amount of leisure time recorded in North America than in Europe (Larson and Verma 1999; Wight et al. 2009). Unlike school, household chores or personal care (e.g., sleep or hygiene), it offers room for a wide range of activities. Regardless of geographical location, it is therefore typified by more pronounced inter-individual differences in its content, as well as distinct associations with health and developmental indicators. Some sorts of activities (e.g., organized activities) can be considered as health-enhancing and supporting development (Larson 2000; Mahoney et al. 2006). Oppositely, some specific unstructured activities, such as frequent visits to shopping malls for fun or hanging out in public places on a regular basis, might pose a threat to adolescent health (Caldwell and Faulk 2013).

Engagement in unstructured activities (UA) is frequently associated with problematic outcomes, but not all UA can be labelled as risky (Bradley 2010; Sharp et al. 2015). UA that actually expose youth to health risks have the following characteristics: adult-unsupervised, lack of skill-building aims, taking place in public and especially having a strong socializing character (Mahoney et al. 2004; Osgood et al. 2005; Weerman et al. 2015). Data from both Europe and the U.S. support the conclusion that settings with such features offer adolescents space for engagement in risky behaviours (Augustyn and McGloin 2013; Lee and Vandell 2015) and are appealing to adolescents who are generally more vulnerable to these behaviours (Mahoney et al. 2004; Persson et al. 2007). Indeed, youth who spend a lot of time in such activities with little or no structure have been reported to have higher rates of substance use (Kiesner et al. 2010; Pulver et al. 2015), potentially risky sexual activity (Barnes et al. 2007) and to do worse in school, both in terms of grade point average and honours or recognitions earned (Nelson and Gastic 2009).

Organized leisure-time activities (OLTA) are in fact exactly opposite of such UA, as they are characterized by having a certain structure, a regular schedule, clearly defined goals and rules, focusing on skill-building and being adult-supervised (Larson 2000; Mahoney et al. 2006). In contrast to socializing UA, youth in OLTA experience higher levels of intrinsic motivation and challenge at the same time (Hansen et al. 2003). This promotes a development of initiative, identity formation, building of teamwork skills and social capital (Hansen et al. 2003) and links OLTA to healthy developmental outcomes (Farb and Matjasko 2012). Compared to those not participating in OLTA, participants in OLTA report better health (Badura et al. 2015; Leversen et al. 2012) or school performance
(Badura et al. 2016; Fredricks 2012) and, oppositely, a lower occurrence of health-risk behaviours (Badura et al. 2017; Takakura 2015), as observed in studies from the U.S., Europe and Japan.

As is apparent from the findings described in the two preceding paragraphs, the developmental outcomes of OLTA (i.e., highly structured) and UA are contradictory. However, OLTA and UA obviously are not mutually exclusive categories of leisure time. A noteworthy group of U.S. adolescents participate in OLTA and, at the same time, are involved in a range of UA (Bartko and Eccles 2003; Sharp et al. 2015). However, little is known if (and how) outcomes for those concurrently involved in risky UA and OLTA are distinct from those involved only in UA. An understanding is needed of how the adolescents cope with combining these two sorts of leisure-time activities with 'conflicting' characteristics and outcomes regarding healthrisk behaviours and school performance.

First, our study aimed to assess the associations between three 'risky' UA and indicators of healthy youth development (health-risk behaviours and academic achievement). Given the gender, age, as well as socioeconomic differences both in the leisure time content (Badura et al. 2015; Sharp et al. 2015) and health-risk behaviours (Inchley et al. 2016), we checked if these mentioned confounding factors modified the associations. Last, we also investigated the degree to which participation in OLTA changed these associations and how adolescents differed regarding the above indicators according to their involvement in unstructured and organized leisure-time activities.

\section{Methods}

\section{Sample and procedure}

Our data come from the Czech Health Behaviour in Schoolaged Children (HBSC) study, which was conducted between April and June 2014. The surveyed schools were randomly selected from the database of Ministry of Education, Youth and Sports of the Czech Republic. Out of the 244 schools approached after stratification by region and ratio of primary and secondary schools, 243 gave consent to conduct the survey. At each of the participating schools, one class from the 5th, 7th and 9th grades (corresponding to age categories 11,13 , and 15 years) was then picked up at random. The questionnaires were administered by trained research assistants during regular class time and in the absence of teachers to minimize potential response bias. Participation in the study was voluntary and anonymous, with no incentives offered to respondents. Prior to administration of the questionnaires, the respondents were notified about the possibility to opt out. The Ethics Committee of the Faculty of 
Physical Culture, Palacky University, Olomouc, approved the study design (No. 57/2014).

There were 16,298 pupils registered in the surveyed classes, and 14,539 of them completed the questionnaires. Thirty pupils refused to take part in the survey, and 1729 pupils were not present at school during the survey, with the most common reason being an illness. Then, we selected only 13- and 15-year-old adolescents, because the questions on UA were not asked to those aged 11 years. Finally, we excluded respondents who were classified as age outliers (e.g., a 15-year-old completing the questionnaire for 7th graders/13-year-olds) or failed to provide data on gender, OLTA or UA. Those missing one or two responses out of the three UA items were only included in the analyses if we could unambiguously classify them as highly engaged in $\mathrm{UA}$, i.e., one of their valid responses was daily or two of their valid responses were weekly or more often.. The final sample comprised 6935 adolescents (49.1\% boys).

\section{Measures}

We investigated involvement in three various peer-oriented UA. The respondents were asked how often they (a) met their friends after 8 o'clock, (b) visited shopping malls for fun or distraction, (c) hung out with their friends in their neighbourhood, park, at playgrounds, etc. We then categorized them into those doing these activities weekly or more often versus those doing them less frequently. We assessed these three activities separately and also derived a composite variable of being involved in any of the unstructured activities on a daily basis or in at least two such activities at least weekly as an indicator of high engagement in UA.

Regarding OLTA, the respondents indicated whether they participated in the following six types of activities: team sports, individual sports, art schools, youth organizations, leisure centres or after-school clubs, and church meeting/ singing. Those involved in at least one OLTA were categorized as participants, while the rest as non-participants. Last, we split the adolescents into four categories based on their leisure-time activities: (1) involved neither in OLTA nor UA, (2) involved only in OLTA, (3) involved both in OLTA and UA, and (4) involved only in UA.

We used four dependent variables in our analyses from the pool of the HBSC mandatory questions (Currie et al. 2014) and dichotomized them according to the most recent HBSC international report (Inchley et al. 2016). Academic achievement was measured using the question: In your opinion, what does your class teacher think about your performance compared to your classmates? The responses were dichotomized as above-average achievement (very good/good) versus the remainder (average/below average).
Current smoking was assessed by the question: How often do you smoke tobacco at present? Four response categories were dichotomized as every day or at least once a week versus less than once a week or I do not smoke.

Drunkenness was assessed by the question: In the last 30 days, have you had so much alcohol that you were really drunk? The respondents were split into those who indicated being drunk at least once in the last 30 days versus those not being drunk in the last 30 days.

Last, we investigated lifetime experience with early sexual intercourse. This was done using the question Have you ever had sexual intercourse (sometimes this is called "making love", "having sex", etc.)?, with dichotomous response option yes versus no. The question was asked only to 15 -year-olds.

Socioeconomic status of adolescents' families served as a control variable in our analyses. It was assessed using the Family Affluence Scale (FAS) developed for the purposes of the HBSC study (Currie et al. 2014). The responses on six items (car ownership, holidays abroad, having one's own bedroom, number of computers in the household, number of bathrooms, and dishwasher ownership) were summed up. We then transformed the sum into a fractional rank score (0-1) (Elgar et al. 2017), with a higher value indicative of a higher level of affluence.

\section{Statistical analyses}

First, we described the sample, its involvement in UA and OLTA, its self-reported academic achievement and engagement in health-risk behaviours. The statistical significance of genderand age differences was examined by Chi-square tests.

Second, we assessed the associations of specific UA (both the separate activities and the composite variable) with academic achievement and health-risk behaviours using binary logistic regression. This was done in five steps-a crude model (Model 1), adjusted for age and gender (Model 2) and further adjusted for socioeconomic status, as indicated by FAS (Model 3). For the composite variable (at least on UA daily or at least two UA weekly), we also tested the interaction with the association of gender (Model 4) and of age category (Model 5).

Next, we tested the 'buffering effect' of OLTA on the associations of UA (participation in at least two of them weekly) with academic achievement and health-risk behaviours. The OLTA variable was added to the model, and the 'buffering effect' was assessed by the interaction between OLTA and high engagement in UA. To assess the stability of our results, we also ran the regression analyses using the pattern of OLTA participation, as previously derived by cluster analysis (Badura et al. 2015), which is indicative of the breadth of such participation. The outputs were very similar to those reported in the paper, so for sake 
Table 1 Description of the study population: rates of respondents' involvement in unstructured and organized activities, health-risk behaviours and self-reported academic achievement by gender and age category; health behaviour in school-aged children study (HBSC), Czech Republic, 2013-2014

$\begin{array}{llllll}\text { Gender } & \text { Girl }(n=3527) & \begin{array}{l}\text { Age } \\$\cline { 1 - 2 } \text {$Boy }(n=3408)\end{array} & \begin{array}{l}\text { Total } \\ (n=3415)\end{array} & \begin{array}{l}\text { 15 years } \\ (n=3520)\end{array}\end{array}$

\section{Unstructured activities}

Hanging out (several times a week)

Visiting shopping malls for fun (several times a week)

Meeting after 8 p.m. (at least weekly)

High overall UA engagement (at least one UA daily or two at least weekly)

Organized activities

Organized activities (at least one)

Dependent variables

Current smoking (weekly)

Drunkenness in the last 30 days (once or more)

Sexual intercourse ${ }^{\mathrm{a}}$ (yes)

Academic achievement (average or worse)

$\begin{array}{lllllr}1548(45.4 \%) & 1884(53.4 \%)^{*} & 1719(50.3 \%) & 1713(48.7 \%) & 3432(49.5 \%) & 2 \\ 818(24.0 \%) & 1120(31.8 \%)^{*} & 1027(30.1 \%)^{*} & 911(25.9 \%) & 1938(27.9 \%) & 1 \\ 626(18.5 \%)^{*} & 499(14.2 \%) & 363(10.7 \%) & 762(21.8 \%)^{*} & 1125(16.3 \%) & 36 \\ 1044(30.6 \%) & 1336(37.9 \%)^{*} & 1155(33.8 \%) & 1225(34.8 \%) & 2380(34.3 \%) & 0 \\ & & & & & \\ 2732(80.2 \%)^{*} & 2719(77.1 \%) & 2857(83.7 \%)^{*} & 2594(73.7 \%) & 5451(78.6 \%) & 0 \\ 299(8.8 \%) & 378(10.8 \%)^{*} & 149(4.4 \%) & 528(15.1 \%)^{*} & 677(9.8 \%) & 36 \\ 415(12.5 \%) & 400(11.6 \%) & 180(5.4 \%) & 635(18.5 \%)^{*} & 815(12.0 \%) & 153 \\ 359(21.2 \%) & 423(24.3 \%)^{*} & N / A & 782(22.8 \%) & 782(22.8 \%) & 86 \\ 1603(47.2 \%) * & 1453(41.5 \%) & 1511(44.5 \%) & 1545(44.1 \%) & 3056(44.3 \%) & 42\end{array}$

UA unstructured activities; N/A not available; \% represents relative rate of valid responses

*Statistically significant $(p<0.05)$ difference in relative rates by gender or age per variable-based on $\chi^{2}$ tests

${ }^{\mathrm{a}}$ The item was present only in the questionnaire version for 15 -year-olds

of brevity we used the simple dichotomous OLTA variable (at least one OLTA vs. none) in the end.

Lastly, we ran the logistic regression with four categories for the combination of OLTA and UA involvement as independent variables (with those involved only in OLTA and UA concurrently as a reference category) to assess the differences between adolescents involved both in OLTA and UA and the rest of the sample, especially those involved only in UA.

Multilevel analyses of the risk behaviours and schoolrelated outcomes on the Czech 2013/2014 HBSC sample did not indicate the data to cluster by school (Badura et al. 2016, 2017). For this reason, we used ordinary single-level regression models to assess the associations in the present study.

\section{Results}

\section{Involvement in unstructured and organized leisure-time activities}

Out of the three investigated UA, hanging out with friends was the most prevalent one (Table 1). Approximately, half of the respondents indicated doing it several times a week. Around a quarter of them visited shopping malls for fun regularly, and $16 \%$ met their friends after 8 o'clock in the evening, with the latter activity being significantly more common among 15-year-olds than among younger adolescents. Slightly over one-third of the respondents reported being involved in any of these UA on a daily basis or two or more UA at least weekly. Regarding OLTA, almost $80 \%$ of respondents took part in one or more such activity, with slightly higher rates in boys than in girls, and in 13 -year-olds than in 15-year-olds.

\section{Unstructured activities, health-risk behaviours and academic achievement}

Table 2 presents odds ratios (OR) and 95\% confidence intervals $(95 \% \mathrm{CI})$ for the associations of the three selected UA with self-reported health-risk behaviours and academic achievement. Involvement in any of these three activities was significantly associated with higher odds for regular smoking, being drunk recently, having sexual intercourse, and low academic achievement. ORs for the univariable model (Model 1-not shown) and the models adjusted for the gender and age category (Model 2) and additionally 
Table 2 Odds ratios (OR) and 95\% confidence intervals (CI) for low self-reported academic achievement, substance use and experience with sexual intercourse for adolescents engaged in unstructured leisure-time activities versus those not involved in these activities; health behaviour in school-aged children study (HBSC), Czech Republic, 2013-2014

\begin{tabular}{|c|c|c|c|}
\hline moking (at & $\begin{array}{l}\text { Drunkenness last } 30 \text { days } \\
\text { (once or more) }\end{array}$ & $\begin{array}{l}\text { Sexual intercourse } \\
\text { (yes) }\end{array}$ & $\begin{array}{l}\text { ic achievemer } \\
\text { or worse) }\end{array}$ \\
\hline DR $(95 \%$ CI $)$ & OR $(95 \% \mathrm{CI})$ & OR $(95 \% \mathrm{CI})$ & OR $(95 \% \mathrm{CI})$ \\
\hline
\end{tabular}

\begin{tabular}{|c|c|c|c|c|}
\hline \multicolumn{5}{|l|}{ MODEL 2 adjusted for gender and age } \\
\hline Hanging out & $3.31 * * *(2.76-3.98)$ & $2.57 * * *(2.19-3.01)$ & $2.33 * * *(1.97-2.75)$ & $1.13 *(1.03-1.25)$ \\
\hline Visiting shopping malls for fun & $2.33 * * *(1.97-2.76)$ & $2.13 * * *(1.82-2.50)$ & $2.30 * * *(1.93-2.73)$ & $1.32 * * *(1.18-1.46)$ \\
\hline Meeting friends after 8 p.m. & $4.28 * * *(3.59-5.10)$ & $4.22 * * *(3.58-4.97)$ & $4.67 * * *(3.90-5.59)$ & $1.47 * * *(1.29-1.67)$ \\
\hline High UA engagement & $4.75 * * *(3.98-5.65)$ & $3.50 * * *(3.00-4.09)$ & $3.66 * * *(3.10-4.33)$ & $1.42 * * *(1.29-1.57)$ \\
\hline \multicolumn{5}{|l|}{$\begin{array}{l}\text { MODEL } 3 \text { adjusted for gender, age } \\
\text { and FAS }\end{array}$} \\
\hline Hanging out & $3.30 * * *(2.75-3.96)$ & $2.57 * * *(2.19-3.02)$ & $2.35 * * *(1.99-2.77)$ & $1.13 *(1.02-1.24)$ \\
\hline Visiting shopping malls for fun & $2.35 * * *(1.99-2.79)$ & $2.13 * * *(1.82-2.49)$ & $2.29 * * *(1.93-2.72)$ & $1.33 * * *(1.19-1.48)$ \\
\hline Meeting friends after 8 p.m. & $4.36 * * *(3.65-5.20)$ & $4.22 * * *(3.58-4.97)$ & $4.66 * * *(3.89-5.58)$ & $1.49 * * *(1.31-1.70)$ \\
\hline High UA engagement & $4.75 * * *(4.00-5.66)$ & $3.50 * * *(3.00-4.09)$ & $3.68 * * *(3.12-4.35)$ & $1.42 * * *(1.29-1.57)$ \\
\hline \multicolumn{5}{|l|}{$\begin{array}{l}\text { MODEL } 4 \text { interaction with gender, } \\
\text { adjusted for age and FAS }\end{array}$} \\
\hline Main effect—gender (boy vs. girl) & $0.79(0.60-1.04)$ & $1.09(0.86-1.36)$ & $0.91(0.72-1.16)$ & $1.36 * * *(1.20-1.53)$ \\
\hline Main effect-high UA engagement & $4.31 * * *(2.84-4.44)$ & $3.23 * * *(2.59-4.03)$ & $3.68 * * *(2.92-4.63)$ & $1.49 * * *(1.29-1.71)$ \\
\hline $\begin{array}{l}\text { Interaction-boy* High UA } \\
\text { engagement }\end{array}$ & $1.24(0.87-1.75)$ & $1.17(0.86-1.59)$ & $1.00(0.72-1.40)$ & $0.90(0.74-1.11)$ \\
\hline \multicolumn{5}{|l|}{$\begin{array}{l}\text { MODEL } 5 \text { interaction with age, } \\
\text { adjusted for gender and FAS }\end{array}$} \\
\hline Main effect-age ( 15 vs. 13 years) & $2.95 * * *(2.17-4.01)$ & $3.71 * * *(2.84-4.84)$ & N/A & $0.97(0.86-1.09)$ \\
\hline Main effect-high UA engagement & $3.27 * * *(2.33-4.60)$ & $2.99 * * *(2.20-4.07)$ & N/A & $1.41 * * *(1.22-1.63)$ \\
\hline $\begin{array}{l}\text { Interaction-age } 15^{*} \text { high UA } \\
\text { engagement }\end{array}$ & $1.64 *(1.11-2.44)$ & $1.23(0.86-1.76)$ & N/A & $1.02(0.83-1.24)$ \\
\hline
\end{tabular}

FAS family affluence scale; $U A$ unstructured activities; N/A not available

$* p<0.05 ; * * p<0.01 ; * * * p<0.001$

${ }^{a}$ The question on sexual intercourse was asked only to 15 -year-olds

FAS (Model 3) hardly differed. Meeting friends after 8 o'clock in the evening showed the strongest associations out of all the dependent variables.

None of the interaction effects of gender on the associations of high engagement in UA was statistically significant. Regarding interaction effects of age category, we observed only 15 -year-olds who reported excessive engagement in UA to have higher odds of current smoking than 13-year-olds (Table 2; Model 5). The interactions with the other dependent variables were not statistically significant.

\section{'Buffering effect' of organized activities on the negative outcomes of unstructured activities}

Next, we assessed the potential 'buffering effect' of OLTA on the negative outcomes related to high engagement in UA (Table 3). We found an interaction effect of OLTA participation with involvement in UA regarding sexual intercourse $(\mathrm{OR}=0.64 ; 95 \% \mathrm{CI}=0.44-0.93)$. This indicates that those engaged highly in UA were less likely to have a sexual experience when involved in OLTA, too, compared with those not involved in OLTA. None of the other interactions was statistically significant.

Lastly, we also investigated the effects per combination of UA and OLTA, with adolescents involved in both OLTA and UA as a reference category, as they were of special interest to the present study (Table 4). Compared with adolescents highly engaged only in UA, those involved both in UA and OLTA had lower odds regarding all four dependent variables assessed; however, the OR regarding recent drunkenness was not statistically significant. Those involved in UA and OLTA concurrently were, nonetheless, more likely to smoke regularly and have experience with sexual intercourse than adolescents involved only in OLTA or uninvolved in any of the leisuretime activities—organized or unstructured-investigated in 
Table 3 Odds ratios (OR) and 95\% confidence intervals (CI) for, substance use, experience with sexual intercourse and low selfreported academic achievement, including the interaction between involvement in unstructured and organized activities; health behaviour in school-aged children study (HBSC), Czech Republic, 2013-/ 2014

\begin{tabular}{|c|c|c|c|}
\hline $\begin{array}{l}\text { Current smoking (at } \\
\text { least weekly) }\end{array}$ & $\begin{array}{l}\text { Drunkenness last } \\
30 \text { days (once or more) }\end{array}$ & Sexual intercourse ${ }^{a}$ (yes) & $\begin{array}{l}\text { emic achievement } \\
\text { age or worse) }\end{array}$ \\
\hline OR $(95 \% \mathrm{CI})$ & OR $(95 \% \mathrm{CI})$ & OR $(95 \%$ CI $)$ & OR $(95 \% \mathrm{CI})$ \\
\hline
\end{tabular}

Main effect

daily or two at least UA weekly)

OLTA (at least one)

$5.35 * * *(3.87-7.40) \quad 4.14 * * *(3.02-5.68)$

$5.16 * * *(3.73-7.14)$

$1.44 * *(1.15-1.81)$

Interaction effect

$0.74 *(0.55-1.00) \quad 1.00(0.77-1.31)$

$1.01(0.77-1.32)$

$0.55^{* * *}(0.47-0.63)$

$\geq 1$ OLTA* high UA involvement

$0.87(0.59-1.27)$

$0.81(0.56-1.16)$

$0.64 *(0.44-0.93)$

$1.01(0.78-1.30)$

The model above was adjusted for gender, age and FAS

FAS family affluence scale; OLTA organized leisure-time activities; UA unstructured activities

$* p<0.05 ; * * p<0.01 ; * * * p<0.001$

${ }^{\mathrm{a}}$ The question on sexual intercourse was asked only to 15 -year-olds

Table 4 Odds ratios (OR) and 95\% confidence intervals (CI) for above-average self-reported academic achievement, substance use and experience with sexual intercourse for various combinations of leisure-time activities; health behaviour in school-aged children study (HBSC), Czech Republic, 2013-2014

\begin{tabular}{|c|c|c|c|c|}
\hline & $\begin{array}{l}\text { Current smoking (at } \\
\text { least weekly) } \\
\text { OR }(95 \% \mathrm{CI})\end{array}$ & $\begin{array}{l}\text { Drunkenness last } \\
30 \text { days (once or } \\
\text { more) } \\
\text { OR }(95 \% \mathrm{CI})\end{array}$ & $\begin{array}{l}\begin{array}{l}\text { Sexual intercourse } \\
\text { (yes) }\end{array} \\
\text { OR }(95 \% \text { CI })\end{array}$ & 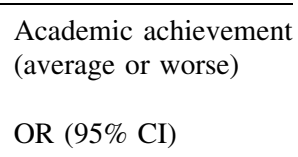 \\
\hline Both OLTA and UA $(n=1905)$ & Ref & Ref & Ref & Ref \\
\hline Only OLTA $(n=3546)$ & $0.22 * * *(0.18-0.27)$ & $0.30 * * *(0.25-0.36)$ & $0.30 * * *(0.25-0.37)$ & $0.69 * * *(0.61-0.77)$ \\
\hline Neither OLTA nor UA $(n=1009)$ & $0.29 * * *(0.22-0.39)$ & $0.30 * * *(0.23-0.39)$ & $0.30 * * *(0.23-0.39)$ & $1.26 * *(1.07-1.47)$ \\
\hline Only UA $(n=475)$ & $1.56 * * *(1.22-1.99)$ & $1.24(0.97-1.59)$ & $1.55 * *(1.19-2.03)$ & $1.81 * * *(1.47-2.23)$ \\
\hline
\end{tabular}

The model above was adjusted for gender, age and FAS

$F A S$ family affluence scale; OLTA organized leisure-time activities; $U A$ unstructured activities

$* p<0.05 ; * * p<0.01 ; * * * p<0.001$

${ }^{a}$ The question on sexual intercourse was asked only to 15 -year-olds

the study. On the other hand, and unlike adolescents only in OLTA, the uninvolved group had higher odds of doing worse at school than those involved both in OLTA and UA.

\section{Discussion}

The present study showed that participation in peer-oriented UA, such as regular hanging out, visiting shopping malls for fun and meeting with friends in the evening, was associated with more frequent smoking, getting drunk, having early sexual intercourse and performing worse in school. This was, in general, independent of respondents' gender, age and socioeconomic status. Concurrent participation in OLTA did not buffer these negative outcomes, except for experience with sexual intercourse. However, adolescents involved only in UA indicated less favourable outcomes on regarding smoking, sexual intercourse and academic achievement than those involved concurrently in UA and OLTA.

Adolescents engaged in the selected UA at least weekly were more prone to substance use, sexual intercourse and low academic achievement compared with their unengaged peers. Our findings are in accordance with a significant body of literature that reported these sorts of activities to be predictive of antisocial and norm-breaking behaviours (Augustyn and McGloin 2013; Haynie and Osgood 2005; Hoeben and Weerman 2016) or linked to worse school performance (Bae and Wickrama 2015; Nelson and Gastic 2009) and increased rates of substance use (Lee and Vandell 2015; Spilkova 2015). UA appear to attract adolescents who generally incline towards health-risk and delinquent behaviours (Mahoney et al. 2004; Persson et al. 2007), and exposure to such peers is one of the frequently discussed 
reasons for the negative outcomes of UA (Haynie and Osgood 2005; Hoeben and Weerman 2016; Svensson and Oberwittler 2010). It is thus possible that risky behaviours and an inclination to UA involvement simply form interrelated features of an underlying personality trait.

However, there is also a complementary explanation for the association of high engagement in UA with health-risk behaviours. It seems that risk-taking in UA is driven mainly by situational motivation and, thus, the root cause lies inherently in the nature of these activities. They provide youth with opportunities for health-risk behaviours (Haynie and Osgood 2005; Hoeben and Weerman 2016; Persson et al. 2007; Siennick and Osgood 2012). This may also explain the fact that adjustment for gender, age and socioeconomic status hardly affected the associations observed. High engagement in unsupervised peer-oriented UA, therefore, appears to be risky across social strata for both adolescent boys and girls.

The 'buffering effect' of concurrent OLTA participation on negative outcomes of engagement in UA was not statistically significant, except for sexual experience. This is somewhat surprising, given the relatively strong evidence linking OLTA to healthy development (Farb and Matjasko 2012). However, it is in line with some authors who warned against exaggeration of the assumed 'positive' effects of participation in OLTA (Fredricks and Eccles 2006; Larson 2000), which could actually be weaker than previously suggested. Moreover, this finding advocates for studying more general patterns of leisure-time use, including a wider array of structured and unstructured leisure-time activities of adolescents when investigating their developmental outcomes (Nelson and Gastic 2009; Sharp et al. 2015).

However, those involved only in UA were more likely to engage in substance use, have sexual intercourse and have worse academic achievement than those involved in both OLTA and UA. Those with only UA and no OLTA might more often feel bored during leisure time or lack of meaningful leisure opportunities. This has been shown to be associated with increased rates of substance use (Weybright et al. 2015) and sexual activity (Miller et al. 2014). On the other hand, those that are concurrently involved in OLTA, implying being a member of a certain social group, might feel less need to stabilize their position through health-risk behaviours (Viau et al. 2015) and might also have less time and fewer opportunities to engage in such behaviours. Nonetheless, it is apparently not enough to participate in OLTA in order to avoid health-risk behaviours, but one should also avoid major UA involvement.

\section{Strengths and limitations}

The main strengths of our study are its large nationally representative sample and use of the well-established
HBSC methodology. However, our study has also some limitations. First, we used self-report questionnaires, which can be sensitive to bias (e.g., due to social desirability or recall bias). We limited this risk by administering the questionnaire anonymously in the absence of teachers. Moreover, most of the measures we used were well validated (Currie et al. 2014). Second, no conclusions regarding causality of the observed associations can be drawn due to the cross-sectional design of the study. Third, our dichotomous measure of OLTA participation can be considered somewhat crude. However, repeating the analyses also with a pattern of OLTA participation yielded similar results as those with dichotomized OLTA. Nonetheless, we still missed information regarding frequency, engagement in, or duration of OLTA participation, which could have provided deeper insight into the topic.

\section{Implications}

Weekly involvement in UA, including hanging out, visiting shopping malls for fun and meeting friends after 8 p.m., was associated with significantly low academic achievement, regular smoking, drunkenness and experience with sexual intercourse. If causal, increase in youth-appealing leisure opportunities could lead to prevention of health-risk behaviours through reduction of UA involvement, because time is a finite resource. This was recently observed by Motamedi et al. (2016), particularly in girls. Next, parental awareness and control of their children's leisure-time activities would perhaps act similarly, as concluded by previous research (Barnes et al. 2007; Kiesner et al. 2010).

Our study provides some hints that participation in OLTA may reduce the occurrence of health-risk behaviours, even though the 'buffering effect' of organized activities on negative outcomes of UA was not significant. More evidence is needed using more detailed measures of OLTA participation, because the measure we used was only dichotomous. Future research should, therefore, focus on particular dimensions of OLTA participation, such as intensity of participation, engagement or quality of program, with more detailed data on the participation probably providing more cues for understanding and intervening.

\section{Conclusions}

Involvement in peer-oriented unstructured activities is strongly associated with an increased risk of smoking, getting drunk, experience with sexual intercourse and worse academic achievement in adolescence. Except for sexual experience, concurrent participation in organized activities did not significantly buffer these negative outcomes, but adolescents involved only in unstructured activities were the most at-risk group. They were more 
likely to smoke, experience sexual intercourse and do worse at school than those involved in organized and unstructured activities concurrently.

\section{Compliance with ethical standards}

Ethical approval All procedures performed in the study were in accordance with the 1964 Helsinki declaration and its later amendments or comparable ethical standards. The study design was approved by the Ethics Committee of the Faculty of Physical Culture, Palacky University, Olomouc (No. 17/2013). Participation in the study was voluntary and anonymous, with no incentives offered to the participants. Parents or legal guardians of the adolescents were notified of the study and its purpose by the school management in advance and could withdraw their child. Prior to administration of the questionnaires, the respondents were also notified of the option to opt out of the study or skip questions that made them uncomfortable.

Funding This work was supported by the Slovak Research and Development Agency under contract No. APVV-15-0012, by a research grant from the Czech Science Foundation under Reg. No. 17-12579S and by the institutional Grant of the Palacký University Olomouc under Reg. No. IGA_FTK_2017_009. The funders had no role in the study design, collection, analysis or interpretations of the data, writing the manuscript, or the decision to submit the paper for publication.

Conflict of interest The authors declare that they have no conflict of interest.

Open Access This article is distributed under the terms of the Creative Commons Attribution 4.0 International License (http://creative commons.org/licenses/by/4.0/), which permits unrestricted use, distribution, and reproduction in any medium, provided you give appropriate credit to the original author(s) and the source, provide a link to the Creative Commons license, and indicate if changes were made.

\section{References}

Augustyn MB, McGloin JM (2013) The risk of informal socializing with peers: considering gender differences across predatory delinquency and substance use. Justice Q 30:117-143. https:// doi.org/10.1080/07418825.2011.597417

Badura P, Geckova AM, Sigmundova D, van Dijk JP, Reijneveld SA (2015) When children play, they feel better: organized activity participation and health in adolescents. BMC Public Health 15:1090. https://doi.org/10.1186/s12889-015-2427-5

Badura P, Sigmund E, Madarasova Geckova A, Sigmundova D, Sirucek J, van Dijk JP, Reijneveld SA (2016) Is participation in organized leisure-time activities associated with school performance in adolescence? PLoS ONE 11(4):e0153276. https://doi. org/10.1371/journal.pone.0153276

Badura P, Sigmundova D, Sigmund E, Madarasova Geckova A, Van Dijk JP, Reijneveld SA (2017) Participation in organized leisuretime activities and risk behaviors in Czech adolescents. Int $\mathrm{J}$ Public Health 62:387-396. https://doi.org/10.1007/s00038-0160930-9

Bae D, Wickrama KAS (2015) Family socioeconomic status and academic achievement among Korean adolescents: linking mechanisms of family processes and adolescents' time use. J Early Adolesc 35:1014-1038. https://doi.org/10.1177/ 0272431614549627

Barnes GM, Hoffman JH, Welte JW, Farrell MP, Dintcheff BA (2007) Adolescents' time use: effects on substance use, delinquency and sexual activity. J Youth Adolesc 36:697-710. https:// doi.org/10.1007/s10964-006-9075-0

Bartko WT, Eccles JS (2003) Adolescent participation in structured and unstructured activities: a person-oriented analysis. J Youth Adolesc 32:233-241. https://doi.org/10.1023/a:1023056425648

Bradley GL (2010) Skate parks as a context for adolescent development. J Adolesc Res 25:288-323. https://doi.org/10. 1177/0743558409357236

Caldwell LL, Faulk M (2013) Adolescent leisure from a developmental and prevention perspective. In: Freire $\mathrm{T}$ (ed) Positive leisure science: from subjective experience to social contexts. Springer, Netherlands, pp 41-60. https://doi.org/10.1007/97894-007-5058-6 3

Currie C, Inchley J, Molcho M, Lenzi M, Veselska Z, Wild F (eds) (2014) Health behaviour in school-aged children (HBSC) study protocol: background, methodology and mandatory items for the 2013/2014 survey. Cahru, St. Andrews

Elgar FJ, Gariépy G, Torsheim T, Currie C (2017) Early-life income inequality and adolescent health and well-being. Soc Sci Med 174:197-208. https://doi.org/10.1016/j.socscimed.2016.10.014

Farb AF, Matjasko JL (2012) Recent advances in research on schoolbased extracurricular activities and adolescent development. Dev Rev 32:1-48. https://doi.org/10.1016/j.dr.2011.10.001

Fredricks JA (2012) Extracurricular participation and academic outcomes: testing the over-scheduling hypothesis. J Youth Adolesc 41:295-306. https://doi.org/10.1007/s10964-011-97040

Fredricks JA, Eccles JS (2006) Is extracurricular participation associated with beneficial outcomes? concurrent and longitudinal relations. Dev Psychol 42:698-713. https://doi.org/10.1037/ 0012-1649.42.4.698

Hansen DM, Larson RW, Dworkin JB (2003) What adolescents learn in organized youth activities: a survey of self-reported developmental experiences. J Res Adolesc 13:25-55. https://doi.org/10. $1111 / 1532-7795.1301006$

Haynie DL, Osgood DW (2005) Reconsidering peers and delinquency: how do peers matter? Soc Forces 84:1109-1130. https:// doi.org/10.1353/sof.2006.0018

Hoeben EM, Weerman FM (2016) Why is involvement in unstructured socializing related to adolescent delinquency? Criminology 54:242-281. https://doi.org/10.1111/1745-9125.12105

Inchley $\mathrm{J}$ et al (eds) (2016) Growing up unequal: gender and socioeconomic differences in young people's health and wellbeing. In: Health Behaviour in School-aged Children (HBSC) study: International report from the 2013/2014 survey. WHO Regional Office for Europe, Copenhagen

Kiesner J, Poulin F, Dishion TJ (2010) Adolescent substance use with friends moderating and mediating effects of parental monitoring and peer activity contexts. Merrill Palmer Q 56:529-556

Larson RW (2000) Toward a psychology of positive youth development. Am Psychol 55:170-183. https://doi.org/10.1037//0003066x.55.1.170

Larson RW, Verma S (1999) How children and adolescents spend time across the world: work, play, and developmental opportunities. Psychol Bull 125:701-736. https://doi.org/10.1037//00332909.125.6.701

Lee KTH, Vandell DL (2015) Out-of-school time and adolescent substance use. J Adolesc Health 57:523-529. https://doi.org/10. 1016/j.jadohealth.2015.07.003

Leversen I, Danielsen AG, Birkeland MS, Samdal O (2012) Basic psychological need satisfaction in leisure activities and 
adolescents' life satisfaction. J Youth Adolesc 41:1588-1599. https://doi.org/10.1007/s10964-012-9776-5

Mahoney JL, Stattin H, Lord H (2004) Unstructured youth recreation centre participation and antisocial behaviour development: selection influences and the moderating role of antisocial peers. Int J Behav Dev 28:553-560. https://doi.org/10.1080/ 01650250444000270

Mahoney JL, Harris AL, Eccles JS (2006) Organized activity participation, positive youth development, and the over-scheduling hypothesis. Soc Policy Rep 20:3-30

Miller JA, Caldwell LL, Weybright EH, Smith EA, Vergnani T, Wegner L (2014) Was Bob Seger right? relation between boredom in leisure and risky sex. Leis Sci 36:52-67. https://doi. org/10.1080/01490400.2014.860789

Motamedi M, Caldwell L, Wegner L, Smith E, Jones D (2016) Girls just want to know where to have fun: preventing substance use initiation in an under-resourced community in South Africa through Health Wise. Prev Sci 17:700-709. https://doi.org/10. 1007/s11121-016-0654-3

Nelson IA, Gastic B (2009) Street ball, swim team and the sour cream machine: a cluster analysis of out of school time participation portfolios. J Youth Adolesc 38:1172-1186. https://doi.org/10. 1007/s10964-008-9372-x

Osgood DW, Anderson AL, Shaffer JN (2005) Unstructured leisure in the after-school hours. In: Mahoney JL, Larson RW, Eccles JS (eds) Organized activities as contexts of development. Lawrence Erlbaum Associates, Mahwah, pp 45-64

Persson A, Kerr M, Stattin H (2007) Staying in or moving away from structured activities: explanations involving parents and peers. Dev Psychol 43:197-207. https://doi.org/10.1037/0012-1649.43. 1.197

Pulver A, Davison C, Pickett W (2015) Time-use patterns and the recreational use of prescription medications among rural and small town youth. J Rural Health 31:217-228. https://doi.org/10. 1111/jrh. 12103

Sharp EH, Tucker CJ, Baril ME, Van Gundy KT, Rebellon CJ (2015) Breadth of participation in organized and unstructured leisure activities over time and rural adolescents' functioning. J Youth Adolesc 44:62-76. https://doi.org/10.1007/s10964-014-0153-4

Siennick SE, Osgood DW (2012) Hanging out with which friends? Friendship-level predictors of unstructured and unsupervised socializing in adolescence. J Res Adolesc 22:646-661. https:// doi.org/10.1111/j.1532-7795.2012.00812.x

Spilkova J (2015) Leisure time preferences and health-risk behavior of teenagers in the post-communist Central European countries. Child Geogr 13:435-450. https://doi.org/10.1080/14733285. 2013.848742

Svensson R, Oberwittler D (2010) It's not the time they spend, it's what they do: the interaction between delinquent friends and unstructured routine activity on delinquency: findings from two countries. J Crim Just 38:1006-1014. https://doi.org/10.1016/j. jcrimjus.2010.07.002

Takakura M (2015) Relations of participation in organized activities to smoking and drinking among Japanese youth: contextual effects of structural social capital in high school. Int J Public Health 60:679-689. https://doi.org/10.1007/s00038-015-0697-4

Viau A, Denault A-S, Poulin F (2015) Organized activities during high school and adjustment one year post high school: identifying social mediators. J Youth Adolesc 44:1638-1651. https:// doi.org/10.1007/s10964-014-0225-5

Weerman FM, Bernasco W, Bruinsma GJN, Pauwels LJR (2015) When is spending time with peers related to delinquency? The importance of where, what, and with whom. Crime Delinq 61:1386-1413. https://doi.org/10.1177/0011128713478129

Weybright EH, Caldwell LL, Ram N, Smith EA, Wegner L (2015) Boredom prone or nothing to do? Distinguishing between state and trait leisure boredom and its association with substance use in South African adolescents. Leis Sci 37:311-331. https://doi. org/10.1080/01490400.2015.1014530

Wight VR, Price J, Bianchi SM, Hunt BR (2009) The time use of teenagers. Soc Sci Res 38:792-809. https://doi.org/10.1016/j. ssresearch.2009.05.009 